\title{
In Vitro Adenylate Cyclase-stimulating Activity Predicts the Occurrence of Humoral Hypercalcemia of Malignancy in Nude Mice
}

\author{
E. C. Weir," K. L. Insogna, ” D. G. Brownstein," N. H. Bander,' and A. E. Broadus" \\ Section of Comparative Medicine* and Department of Internal Medicine," Yale University School of Medicine, New Haven, \\ Connecticut 06510; The West Haven Veterans Administration Medical Center, ${ }^{\ddagger}$ West Haven, Connecticut 06516; and The Memorial \\ Sloan-Kettering Cancer Center and New York Hospital-Cornell Medical Center, New York, New York 10021
}

\begin{abstract}
A number of factors have been proposed as potential mediators of the syndrome of humoral hypercalcemia of malignancy (HHM), but to date no firm cause-and-effect relationship has been established. We attempted to establish such a relationship by determining whether the presence or absence of adenylate cyclase-stimulating activity (ACSA) in the media of cultured tumor cells predicted the occurrence of the syndrome of HHM when these cell lines were grown in nude mice in vivo.

Conditioned media from 35 human renal carcinoma cell lines were surveyed for ACSA in the PTH-sensitive rat osteosarcoma 17/2.8 cell assay. 12 lines were positive (mean, 13.7fold stimulation, range, 3.0 to 44.0 ), and 23 lines were negative (mean, 1.2-fold stimulation, range, 0.9 to 1.5 ). We were successful in establishing five of the positive and six of the negative lines in three to five nude mice per line. Mice implanted with the positive lines uniformly became hypercalcemic (mean serum calcium, $15.8 \mathrm{mg} / \mathrm{dl}$ ), whereas mice implanted with the negative lines uniformly remained normocalcemic (mean serum calcium, $9.5 \mathrm{mg} / \mathrm{dl}$ ), in spite of comparable mean tumor size. Acid-urea tumor extracts from each of four hypercalcemic animals contained potent in vitro ACSA (mean, 15.9-fold stimulation), while 5/5 extracts from normocalcemic animals did not (mean, 1.4-fold stimulation).

Our study demonstrates that in this model system in vitro ACSA is a reliable predictive marker for HHM in vivo. Whether the protein responsible for this activity is also the mediator of the bone resorption seen in HHM remains to be demonstrated.
\end{abstract}

\section{Introduction}

The mechanisms mediating humoral hypercalcemia of malignancy (HHM) ${ }^{1}$ have not been clearly defined. It appears that PTH itself does not account for most cases of HHM (1), but that the responsible factor is an as yet unidentified protein

Address correspondence to Dr. Weir, Section of Comparative Medicine, Yale University School of Medicine, 375 Congress Ave., P.O. Box 3333, New Haven, CT 06510.

Received for publication 5 March 1987 and in revised form 26 October 1987.

1. Abbreviations used in this paper: ASCA, adenylate cyclase-stimulating activity; bPTH, bovine PTH; HHM, humoral hypercalcemia of malignancy; ROS, rat osteosarcoma.

J. Clin. Invest.

(C) The American Society for Clinical Investigation, Inc. 0021-9738/88/03/0818/04 \$2.00

Volume 81, March 1988, 818-821 which causes hypercalcemia in vivo by stimulation of osteoclastic bone resorption (2) and possibly by increasing renal tubular calcium reabsorption $(3,4)$. Although the nature of this humoral factor(s) remains unknown, three potential mediators have been proposed. These include PTH-like peptides (5), transforming growth factor-like molecules $(6,7)$, and bone-resorbing proteins distinct from either of these two classes of proteins (8).

Since the relationship between PTH-like activity in vitro and hypercalcemia in vivo is unresolved, we attempted to examine this relationship by determining whether the presence or absence of adenylate cyclase-stimulating activity (ACSA) in conditioned media from cultured human renal tumor cells detected in vitro predicted the occurrence of hypercalcemia when these same lines were grown in nude mice. We also examined whether the presence of ACSA in extracts of tumors grown in the mice correlated with the development of hypercalcemia in vivo.

\section{Methods}

Cell lines. 35 human renal cell carcinoma lines from surgical tissue were established in culture between 1974 and 1982, as previously described $(9,10)$. Cells were grown in Eagle's MEM supplemented with $7.5 \%$ heat-inactivated fetal bovine serum, $200 \mathrm{IU} / \mathrm{ml}$ penicillin, and $200 \mu \mathrm{g} / \mathrm{ml}$ streptomycin. Cell lines were maintained at $37^{\circ} \mathrm{C}$ in a humidified atmosphere of $5 \% \mathrm{CO}_{2} / 95 \%$ air. Unconcentrated media conditioned for $48 \mathrm{~h}$ by confluent cultures were used to assay for the presence of ACSA.

Tumor production in nude mice. 4-6-wk-old outbred CR:NIH(S) $\mathrm{nu} / \mathrm{nu}$ mice were obtained from the National Institutes of Health, Bethesda, MD. Except where indicated, mice were given water ad lib. and standard rodent chow (autoclavable rodent laboratory chow 5010; Ralston-Purina Co., St. Louis, MO) containing $1.0 \%$ calcium and $0.6 \%$ phosphorus. Before inoculation, adherent cells were removed from tissue culture flasks using a solution containing $0.5 \mathrm{~g} /$ liter trypsin and $0.2 \mathrm{~g} /$ liter EDTA (Gibco, Grand Island, NY) followed by mechanical scraping. Each mouse received a subcutaneous injection of $0.2 \mathrm{ml}$ of culture medium containing $10^{6}$ tumor cells. Each cell line was initially inoculated into two mice.

In those mice in which tumors were established, tumor diameters were measured and blood was obtained from the retro-orbital plexus at 2-4-wk intervals. Tumor size was calculated as length times width. Serum calcium was measured by atomic absorption spectrophotometry (11). Animals carrying hypercalcemia-associated tumors were killed when they became symptomatic due to hypercalcemia. Mice carrying nonhypercalcemia-associated tumors were killed when tumor size was at least $2 \mathrm{~cm}^{2}$. At the time of the killing, all tumors were resected and stored at $-70^{\circ} \mathrm{C}$.

Preparation of tumor extracts. Acid-urea extracts of tumor tissue were prepared as previously described (12). Briefly, frozen tumor tissue was homogenized in $0.1 \mathrm{M}$ Tris, $\mathrm{pH} 7.4$, followed by centrifugation at $15,000 \mathrm{~g}$. The pellet was extracted with $8 \mathrm{M}$ urea, $0.2 \mathrm{~N}$ hydrochloric acid, $0.1 \mathrm{M}$ cysteine, and recentrifuged. The supernatant was dialyzed 
against distilled water and stored frozen before assay. In each case, 100 $\mu \mathrm{l}$ of unconcentrated tumor extract was assayed per well. Protein added per well ranged from 0.69 to $1.09 \mathrm{mg}$.

Detection system for PTH-like ACSA. The detection system for ACSA in conditioned medium and crude tumor extracts was the rat osteosarcoma (ROS) cell assay (ROS assay), which employs a PTHsensitive clonal ROS line (17/2.8) and measures the accumulation of ${ }^{3} \mathrm{H}$ cAMP in response to binding to PTH receptors (13). The detection limit of the assay is $5 \times 10^{-11} \mathrm{M}(1-34)$ bovine PTH (bPTH). In each case, $100 \mu \mathrm{l}$ of unconcentrated conditioned medium was assayed per well. Conditioned medium from selected lines (see text) which stimulated the ROS assay were also assayed in the presence of the synthetic competitive PTH antagonist $\mathrm{Nle}^{8,18}$, $\mathrm{Tyr}^{34}$ bPTH-(3-34) amide (Peninsular Laboratories, Inc., Belmont, CA).

Clinical data on patients of origin. Of those five lines which stimulated the ROS assay and which caused hypercalcemia when grown in nude mice, clinical data were available on three of the patients of origin. Two of these patients displayed severe hypercalcemia, and the third was marginally hypercalcemic. Of the six lines which neither stimulated the ROS assay nor caused hypercalcemia in nude mice, clinical data available on five of the patients of origin indicated that four were normocalcemic and one was slightly hypercalcemic, but suffered from extensive bone metastases.

Necropsy. One tumor-bearing mouse per line was necropsied. Multiple sections of the following bones were examined histologically for metastases: vertebral column, sternum, pelvis, humerus, radius, femur, and tibia. Mice with no histologic evidence of tumor in these sites were considered to be free from metastases.

Statistical analyses. Unless otherwise stated, results are expressed as mean \pm standard deviation. Student's $t$ test for unpaired observations was used for all statistical analyses.

\section{Results}

ACSA of conditioned media. When unconcentrated conditioned media from 35 renal cell carcinoma lines were surveyed for ACSA, 12 lines (34\%) were positive (mean fold stimulation, 13.7, range, 3.0 to 46.0 ) and 23 lines $(66 \%)$ were negative (mean fold stimulation, 1.2, range, 0.9 to 1.5) (Fig. 1). One positive ("ROS positive") and seven negative ("ROS negative") lines were assayed on two occasions, and five "ROS positive" and two "ROS negative" were assayed on multiple occasions. These results were found to be entirely reproducible over the course of two years, indicating no crossover between positive and negative lines.

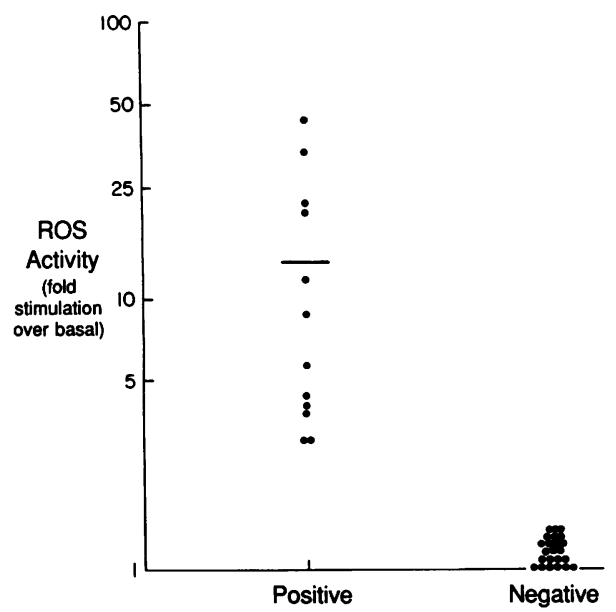

Figure 1. In vitro ACSA in unconcentrated conditioned medium from 35 renal cell carcinoma lines. Results are expressed as fold stimulation over basal and are displayed on a log scale.
To examine whether ACSA was due to specific interaction with the PTH receptor, conditioned media from those lines that were positive in the ROS assay and were subsequently established in nude mice were assayed in the presence of $\mathrm{Nle}^{8,18}, \mathrm{Tyr}^{34}$ bPTH-(3-34) amide. In all cases, activity was inhibited at an antagonist concentration of $10^{-6} \mathrm{M}$ (mean fold stimulation before inhibition, 11.6, range, 3.2 to 22.2; after inhibition, 2.2, range, 1.9 to 2.5). The dose-response curves of ACSA for three of those lines were examined, and closely paralleled that of synthetic bPTH-(1-34) (Fig. 2).

Tumor growth in mice. We attempted to grow a total of 18 lines in mice, 8 of these being ROS positive and 10 ROS negative. We were successful in establishing five ROS-positive and six ROS-negative lines in a total of three to five mice per line, with the exception of one positive line that was lost through contamination after being established in one mouse. The mean ROS activity of the positive lines established in mice was 8.7-fold stimulation over basal (range, 3.0 to 22.0), and of the negative lines, 1.2-fold (range, 1.0 to 1.5) (Table I). These values were not significantly different from the mean ROS activities of the entire collection of positive and negative lines $(P>0.25)$.

Although there was variation in growth rate among ROSpositive lines and among ROS-negative lines, there appeared to be no overall difference in growth rate between the group of positive lines and the group of negative lines (data not shown).

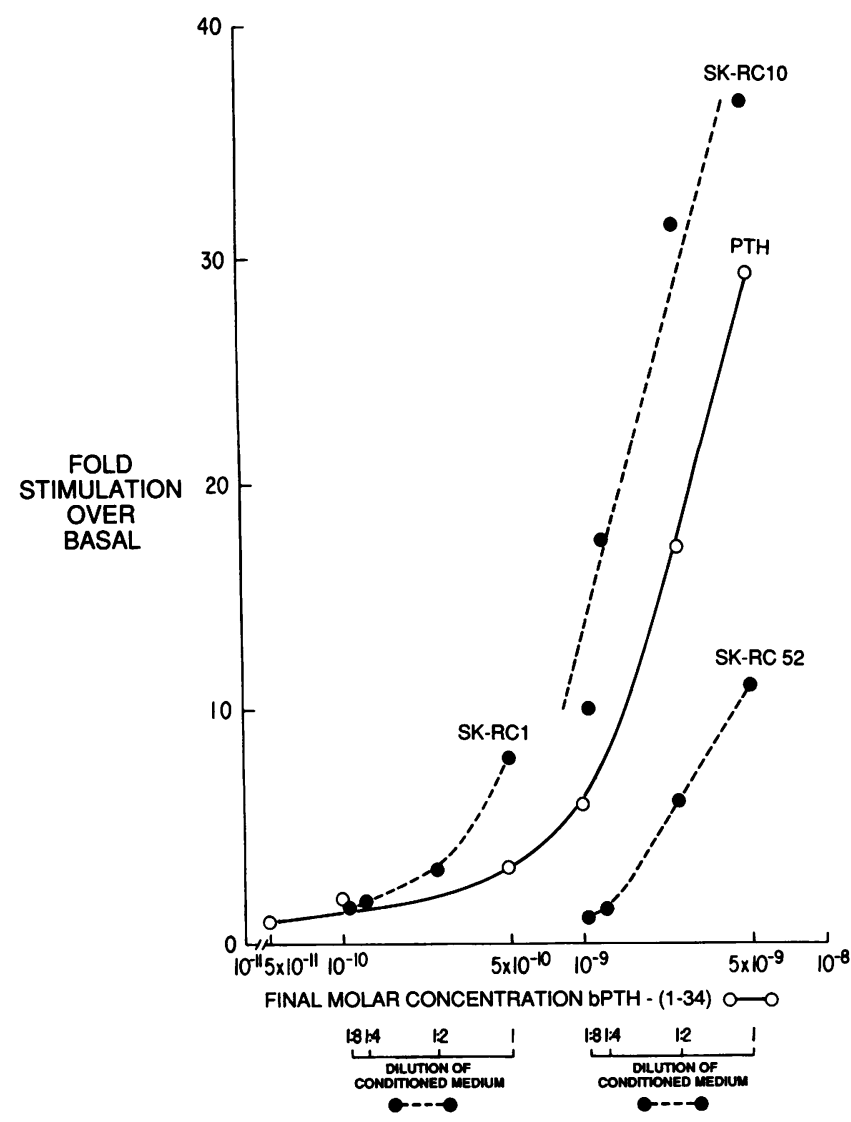

Figure 2. ACSA of synthetic bPTH-(1-34) and conditioned media from three ROS-positive lines. ACSA is expressed as fold stimulation over basal and is the mean of two determinations. At maximum concentrations assayed, protein added per well was $0.61 \mathrm{mg}$ for SK-RC1, $0.68 \mathrm{mg}$ for SK-RC 10, and $0.52 \mathrm{mg}$ for SK-RC52. 
Table I. In vitro ACSA in Conditioned Media from Cultured Human Renal Carcinoma Cell Lines Successfully Established in Nude Mice, and Serum Calcium Levels in Animals Bearing the Same Lines

\begin{tabular}{|c|c|c|c|c|c|}
\hline ROS assay category & $\begin{array}{l}\text { Number of } \\
\text { cell lines }\end{array}$ & $\begin{array}{l}\text { Mean ROS activity } \\
\text { (fold stimulation } \\
\text { over basal) }\end{array}$ & $\begin{array}{l}\text { Number of } \\
\text { animals }\end{array}$ & Mean tumor size & $\begin{array}{l}\text { Mean serum } \\
\text { calcium }\end{array}$ \\
\hline & & & & $\mathrm{cm}^{2}$ & $m g / d l$ \\
\hline Positive & 5 & 8.7 & 16 & $4.6 \pm 1.8$ & $15.8 \pm 2.1$ \\
\hline Negative & 6 & 1.2 & 27 & $5.3 \pm 2.3$ & $9.5 \pm 1.1$ \\
\hline$P$ & & $<0.05$ & & NS & $<0.001$ \\
\hline
\end{tabular}

Measurement of serum calcium and tumor size revealed that the mice implanted with ROS-positive cell lines uniformly became hypercalcemic when tumor size reached $2 \mathrm{~cm}^{2}$, and the mice became increasingly hypercalcemic as tumors increased in size (Fig. 3). By contrast, ROS-negative lines failed to cause hypercalcemia in mice at any point during tumor growth. At time of killing, the mice bearing ROS-positive tumors were significantly hypercalcemic (mean serum calcium, $15.8 \mathrm{mg} / \mathrm{dl}$ ) compared with those bearing ROS-negative tumors (mean serum calcium, $9.5 \mathrm{mg} / \mathrm{dl}$ ) in spite of comparable mean tumor size (Table I).

To examine in more detail the mechanism of the hypercalcemia, and to exclude metasatic bone destruction, one tumorbearing mouse per line was submitted for necropsy. There was no evidence of skeletal or visceral metastases.

To exclude intestinal hyperabsorption as the cause of hypercalcemia, three hypercalcemic mice carrying tumors from three different ROS-positive tumors were fed a calcium-deficient diet containing $0.02 \%$ calcium and $0.4 \%$ phosphorus for $14 \mathrm{~d}$. In each case, despite dietary calcium restriction, serum calcium levels increased with tumor growth (mean serum calcium before calcium deficient diet, $14.5 \mathrm{mg} / \mathrm{dl}$, after calciumdeficient diet, $17.0 \mathrm{mg} / \mathrm{dl}$ ).

$A C S A$ in tumor extracts. Acid-urea tumor extracts from

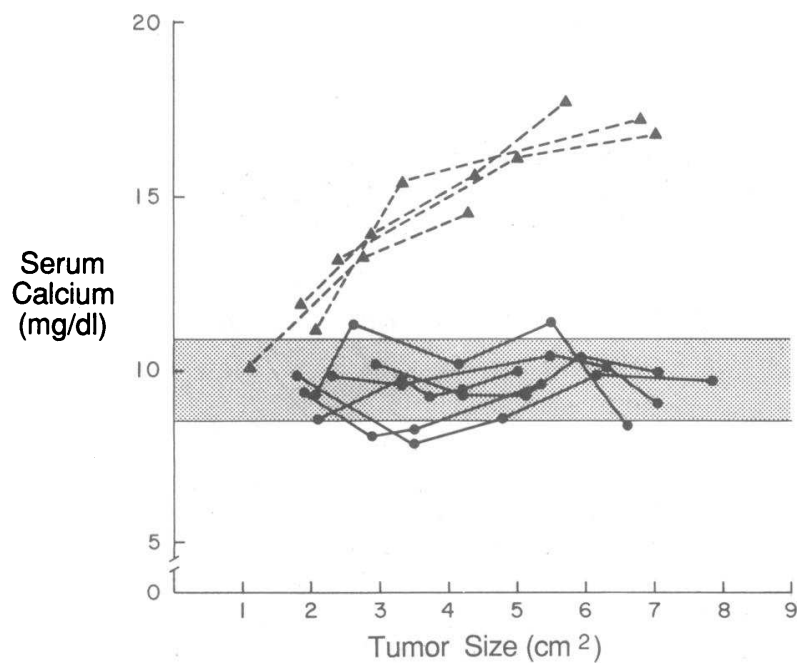

Figure 3. Relationship of serum calcium and tumor size in nude mice bearing four ROS-positive and six ROS-negative cell lines. Mean serum calcium levels of two to five mice per line are shown. The normal range for serum calcium (mean $\pm 2 \mathrm{SD}, n=9$ ) is shaded. Line designations for ROS-positive lines were SK-RC 1, 10, 15, 38, and 52, and for ROS-negative lines SK-RC 17, 18, 29, 31, 42, and 49. four hypercalcemic mice bearing four different ROS-positive lines and five nonhypercalcemic mice carrying five different ROS-negative lines were assayed for ACSA. All tumor extracts from hypercalcemic animals contained moderate to marked ACSA (mean fold stimulation, 15.9, range, 4.6 to 13.2), whereas extracts from nonhypercalcemic mice were devoid of activity (mean fold stimulation, 1.4, range, 1.2 to 1.6).

\section{Discussion}

The role of PTH-like adenylate cyclase-stimulating proteins in the pathogenesis of HHM is unclear, and results of studies attempting to clarify this relationship have been conflicting. In one study (14), two tumors with no PTH-like activity in vitro caused hypercalcemia when grown in animals, whereas one tumor with substantial PTH-like activity in vitro failed to cause hypercalcemia in nude mice, suggesting that there is no cause-and-effect relationship between the PTH-like factor and hypercalcemia. By contrast, in another recent study (5), 18 of 20 tumor extracts from patients with HHM displayed PTHlike activity in vitro, whereas only 4 of 27 control tumors contained detectable activity, suggesting that the PTH-like activity in these tumors is strongly correlated with the hypercalcemia seen in the patients of origin.

In our study, conditioned medium from 12 of 35 renal cell carcinoma lines surveyed reproducibly stimulated the PTHsensitive ROS assay. This activity exhibited a dose-response curve which closely paralleled that of PTH and was completely inhibited by the competitive PTH inhibitor $\mathrm{Nle}^{8,18}, \mathrm{Tyr}^{34}$ bPTH-(3-34) amide, suggesting that the adenylate cyclasestimulating factor found in conditioned medium produces its effect by specific interaction with PTH receptors in vitro. The present data suggest that this activity is closely related to the tumor-derived factor(s) which causes hypercalcemia in vivo. Thus, the presence of in vitro ACSA in conditioned medium from lines that grew in nude mice uniformly predicted the occurrence of hypercalcemia in these animals, whereas mice implanted with lines negative for this activity remained normocalcemic, despite comparable tumor growth. In addition, when tumor extracts from nine lines were examined for ACSA, the presence or absence of ACSA correlated precisely with the presence or absence of hypercalcemia in tumor-bearing mice.

Necropsy examination of tumor-bearing mice showed no evidence of bone metastases. This suggested that hypercalcemia in these animals was mediated by a tumor-derived humoral factor and not by local osteolysis. In addition, failure of a calcium-deficient diet to influence the serum calcium con- 
centration in tumor-bearing animals suggested hypercalcemia was not attributable to intestinal calcium hyperabsorption. These findings concur with those of Strewler et al., who showed that hypercalcemia in nude mice bearing a human renal cell carcinoma was humorally mediated and that increased bone resorption was the cause of the hypercalcemia $(15,16)$.

Our study demonstrates that in this model system, in vitro ACSA is a reliable marker for HHM in vivo. Whether the protein responsible for this activity is also the mediator of the bone resorption seen in HHM remains to be demonstrated.

\section{Acknowledgments}

The authors thank Ms. Rosemary Ramsewak and Ms. Babara Exler for their expert technical assistance and Ms. Laurie Flaherty and Ms. Ruth Berger for their superb secretarial skills.

This work was supported by grants AM-30102, AM-21707, RR-00393, and POL-CA-33049-04 from National Institutes of Health, and by a grant from the Research Service of the Veterans Administration.

\section{References}

1. Simpson, E. L., G. R. Mundy, S. M. D'Souza, K. J. Ibbotson, R. Bockman, and J. W. Jacobs. 1983. Absence of parathyroid hormone messenger RNA in non-parathyroid tumors associated with hypercalcemia. N. Engl. J. Med. 309:325-330.

2. Stewart, A. F., A. Vignery, A. Silvergate, N. D. Ravin, V. LiVolsi, A. E. Broadus, and R. Baron. 1982. Quantitative bone histomorphometry in humoral hypercalcemia of malignancy: uncoupling of bone cell activity. J. Clin. Endocrinol. Metab. 55:219-227.

3. Hirschel-Scholz, S., J. Caverzasio, R. Rizzoli, and J.-Ph. Bonjour. 1986. Normalization of hypercalcemia associated with a decrease in renal calcium absorption in Leydig cell tumor-bearing rats treated with WR-2721. J. Clin. Invest. 78:319-322.

4. Rizzoli, R., J. Cavarzasio, H. Fleish, and J. P. Bonjour. 1986. Parathyroid hormone-like changes in renal calcium and phosphate reabsorption induced by Leydig cell tumor in thyroparathyroidectomized rats. Endocrinology. 119:1004-1009.

5. Stewart, A. F., K. L. Insogna, W. J. Burtis, A. Aminiafshar, T. Wu, E. C. Weir, and A. E. Broadus. 1986. Frequency and partial characterization of adenylate cyclase-stimulating activity in tumors associated with humoral hypercalcemia of malignancy. J. Bone Min. Res. 1:267-276.

6. Ibbotson, K. J., S. M. D'Souza, K. W. Ng, C. K. Osborne, M. Niall, T. J. Martin, and G. R. Mundy. 1983. Tumor-derived growth factor increases bone resorption in a tumor associated with humora hypercalcemia of malignancy. Science (Wash. DC). 221:1291-1294.

7. Mundy, G. R., K. J. Ibbotson, S. M. D'Souza, E. L. Simpson, J. W. Jacobs, and T. J. Martin. 1984. The hypercalcemia of cancerclinical implications and pathogenic mechanisms. N. Engl. J. Med. 310:1718-1727.

8. Bringhurst, F. R., V. Varner, and G. V. Segre. 1982. Cancer-associated hypercalcemia: characterization of a new bone-resorbing factor. Clin. Res. 30:386A. (Abstr.)

9. Ueda, R., H. Shiker, M. Pfreundschuh, T. Takahasahi, L. T. C. Li, W. F. Whitmore, H. F. Oettgen, and L. J. Old. 1979. Cell surface antigens of human renal cell cancer defined by autologous typing. $J$. Exp. Med. 150:564-579.

10. Bander, N. H. Renal cancer: a model system for the study of human neoplasia. In Monograph: Genes and Antigens in Cancer Cells: the Monoclonal Antibody Approach. Series: Contributions to Oncology. G. Riehthmuller, H. Koprowski, S. VonKleist, and H. Munk, editors. S. Karger, Basel. 104-120.

11. Zettner, A., and D. Seligson. 1964. Application of atomic absorption spectrophotometry in the detection of calcium in serum. Clin. Chem. 10:869-890.

12. Stewart, A. F., K. L. Insogna, D. Goltzman, and A. E. Broadus. 1982. Identification of adenylate cyclase-stimulating activity and cytochemical bioactivity in extracts of tumors from patients with humoral hypercalcemia of malignancy. Proc. Natl. Acad. Sci. USA. 80:14541458.

13. Rodan, S. B., K. L. Insogna, A. M. Vignery, A. F. Stewart, A. E. Broadus, S. M. D'Souza, D. R. Bertolini, G. R. Mundy, and G. A. Rodan. 1983. Factors associated with humoral hypercalcemia of malignancy stimulate adenylate cyclase in osteoblastic cells. J. Clin. Invest. 72:1511-1515.

14. Gutierrez, G. E., M. S. Katz, S. D'Souza, and K. Ibbotson. 1985. Relationship of PTH-like factors and bone resorbing activity from tumors associated with the humoral hypercalcemia of malignancy. Calcif. Tissue Int. 37:144. (Abstr.)

15. Strewler, G. J., R. D. Williams, and R. A. Nissenson. 1983. Human renal carcinoma cells produce hypercalcemia in the nude mouse and a novel protein recognized by parathyroid hormone receptors. J. Clin. Invest. 71:769-774.

16. Strewler, G. J., T. J. Wronski, B. P. Hollaran, S. C. Miller, S. C. Leung, R. D. Williams, and R. A. Nissenson. 1986. Pathogenesis of hypercalcemia in nude mice bearing a human renal carcinoma. Endocrinology. 119:303-310. 